\title{
Assay Suitability for Natural Product Screening: Searching for Leads to Fight Alzheimer's Disease
}

Author

Affiliation
Mervi Vasänge

Pharmaceutical Sciences, Åbo Akademi University, Turku, Finland

\author{
Key words \\ - phenotypic assay \\ - target-based assay \\ - reductionistic \\ - Alzheimer's disease \\ - acetylcholinesterase \\ - amyloid \\ oxidative stress
}

received April 13, 2014

revised August 20, 2014

accepted August 25, 2014

\section{Bibliography}

Dol http://dx.doi.org/

10.1055/s-0034-1383063

Published online September 15,

2014

Planta Med 2014; 80:

1200-1209 @ Georg Thieme

Verlag KG Stuttgart · New York .

ISSN 0032-0943

\section{Correspondence}

\section{Docent Dr. Mervi Vasänge}

Department of Biosciences,

Pharmaceutical Sciences,

Åbo Akademi University, Biocity

Artillerigatan 6

20520 Turku

Finland

Phone: + 358451655989

mvasange@abo.fi

\section{Abstract \\ $\nabla$}

Phenotypic and target-based approaches represent two principal strategies for identifying new bioactive compounds. In this review, differences between these approaches, as well as strengths and limitations thereof, are described by examples from the therapeutic area of Alzheimer's disease. Some of the central mechanisms of the disease that today are targets of screening campaigns are described. These mechanisms include acetylcholinesterase inhibition, amyloid-based approaches, and oxidative stress. Examples of assays using natural products, either as isolated pure compounds, unpurified or partially purified extracts, are given for each mechanism. Further, the article presents and discusses the pros and cons of both target-based and phenotypic approaches for the chosen mechanisms. In most cases, a thoroughly biology-driven selection of the used assays can be recommended, especially when taking into account the complexity of the disease in question. However, target-based assays also have their justification as long as there is an awareness of what the assay read-out stands for. A clear recommendation is thus for every researcher to critically consider the aim of their bioactivity screening efforts and to adopt the screening strategies most appropriate for the goals set.

\section{$\nabla$}

Introduction

Speaking in general terms, there are two major reasons for why drugs fail in the clinic: either they do not give the desired treatment effect or they are not safe. For a positive clinical outcome, a drug naturally needs to exert its biological action on a target that is relevant and essential for the disease

\section{Abbreviations}

$\nabla$

AchE: acetylcholinesterase

AD: $\quad$ Alzheimer's disease

APP: amyloid precursor protein

$A \beta$ : $\quad$ amyloid beta

BACE1: $\quad \beta$-secretase 1

BchE: butyrylcholinesterase

CHO: Chinese hamster ovary cells

CNS: $\quad$ central nervous system

DCFH-DA: dichloro-dihydro-fluorescein diacetate

DMPD: $\quad \mathrm{N}, \mathrm{N}$-dimethyl-p-phenylenediamine

DPPH: 2,2-diphenyl-1-picrylhydrazyl

DTNB: $\quad 5,5^{\prime}$-dithiobis(2-nitrobezoic acid)

FDA: $\quad$ Food and Drug Administration

FRET: fluorescence resonance energy transfer

GPCR: G-protein coupled receptor

HTS: $\quad$ high throughput screening

iNOS: inducible nitric oxide synthase

LPS: lipopolysaccharide

MTT: 3-(4,5-dimethylthiazol-2-yl)-2,5-diphenyltetrazoliumbromide

NME: new molecular entity

NO: $\quad$ nitric oxide

NP: $\quad$ natural product

NSAID: nonsteroidal anti-inflammatory drug

ORAC: oxygen radical absorption capacity

ROS: $\quad$ reactive oxygen species

SO: $\quad$ superoxide anion

tBTH: $\quad$ tertiary butyl hydroperoxide

in question. A target, in turn, can commonly be defined as being a biological entity that a compound can modulate through a specific interaction. Specificity and selectivity of interaction are considered essential for both efficacy and safety. Furthermore, a target needs to be 'druggable', meaning that it should be accessible by a small molecule (or larger biological) drug and that the 
binding of these two will result in a biological response that can be measured and quantified both in vitro and in vivo. This 'philosophy' is very much the basis of modern target-based drug discovery.

The most common way of hit identification has been during the last near 25 years through bioactivity-based screening which relies on development of screening assays that specifically measure target-compound interaction. In the next step, the assay is used either in a high-throughput or other smaller screening format for lead molecule identification. This target-driven approach has growingly become challenged by what is called phenotypic screening strategy. A phenotypic set-up could be described as designing assays for some desired effect in a living system, independent of any defined target. In other words, a phenotypic assay does not aim to assess modification of one defined target protein, and thus a specific target-compound interaction will not be default read-out from the screen. Thus the specific and selective interactions, as well as demand for 'druggability' are not a prerequisite here. To a large extent, this bears resemblance to the preHTS era of drug discovery as it, similarly to the physiology-based drug discovery, acknowledges the complexity and integrative nature of biological processes.

\section{Asking the relevant questions}

A landmark article on the original discovery strategy behind registered NMEs by the FDA during the years from 1999 to 2008 has in the last few years started a debate and self-introspection within the pharmaceutical industry and its academic collaborators. In this article, Swinney and Anthony [1] show that for the in total 45 small molecule first-in-class NMEs, 28 (62\%) had their origin in a phenotypic approach, whereas 17 (38\%) were identified in a molecular-targeted drug discovery. The picture is different with the so called 'me-too' drugs that are defined as molecules resembling those already approved by the authorities. For these drugs, molecular-targeted discovery is more common.

These two principal approaches for compound screening, targetbased and phenotypic, differ in 'what comes first' [2]. Phenotypic can be defined as 'function first' since it starts with the observation of an organism displaying a certain phenotype, for example, in a disease state. Compounds are then screened to find those that can alter the phenotype. The mechanism for how this is achieved will be identified later - and sometimes very late (or not at all!). The target-based approach, 'gene first', initiates with identifying the gene that codes for a protein target. The screen that follows will accordingly select for high-affinity binding compounds. Sequential and more complex assays that follow are set up in order to confirm the primary activity in tissues and organisms. These two strategies, target-based (also called reductionistic) and phenotypic drug discovery, promote assays of distinctly different kind. The present review proposes that a screening assay could metaphorically be seen as a question, and that the two approaches, reductionistic and phenotypic, can be considered to ask their questions in different ways. A reductionistic inquiry is capable of in good detail defining what it is looking for, whereas the phenotypic one phrases it in a way that leaves the answer options more open. Consequently, deciding on which sort of question needs to be answered with each assay set-up is the first step of the process.

\section{Natural products}

Looking at the origin of screened compounds over time, the explosion in the volume of HTS screens, technology development and the parallel vast increase in combinatorial chemistry efforts since the early 1990s has simultaneously led to the cessation of $\mathrm{NP}$ research at almost all the major pharmaceutical companies. Certainly the reasons for this are several, but a suggested major one is the incompatibility of natural product mixtures with HTS and other detection techniques [3]. On the other hand, when analyzing the origin of the registered drug compounds over the period of 1981-2010, Newman and Cragg [4] demonstrate that up to $50 \%$ of these can be traced to a natural product, a semi-synthetic derivative or a natural-product-inspired total synthesis effort. In another recent publication, Mishra and Tiwari [5] report that there have been 19 approvals of natural-product-derived drugs during the period of January 2005 to April 2010, indicating that in spite of the dismissal of natural products in big pharma screening efforts, natural products still continue to provide new drugs today.

These findings might reflect the fact that natural products represent a broader chemical space than the synthetic libraries that often are built around well-known target-classes such as GPCRs. When the target disease mechanisms are more complex, or maybe even unknown, the compounds that will be successful in their treatment might need to emerge from outside the common, small molecule-defined chemical space [6]. As this line of reasoning is growing in acceptance [7-9], it is likely to push natural products that previously have proven successful modulators of difficult targets once again towards being common constituents in screening libraries.

An additional argument for natural product screening is the fact that many of the diseases for which new drugs are needed have multifactorial background. For treatment efficacy, modulation of robust biochemical networks, rather than single target, is likely to be needed [2]. This could be achieved either by hitting on multiple targets with compound mixtures (cocktails) or identifying promiscuous compounds that simultaneously modulate several targets (polypharmacology). Both these are approachable with natural products and phenotypic screening.

The target-based and phenotypic assays that are reviewed in the present article all have the goal to find compounds for treatment of AD. This therapeutic area represents a field with successful natural products research, namely inhibitors of AchE. However, for the majority of the potential target mechanisms in $\mathrm{AD}$, natural products are still new and the research today is emerging. The examples of assays presented here comprise target mechanisms that at present are under investigation as possible disease treating options, and each assay category is introduced with a brief biological background. All the examples given describe work that has been done with natural products. The aim is not to present an exhaustive survey of the assays used in NP screening but rather to provide an overview of some of the more recent available assays, target-based and phenotypic, with their assets and limitations. Furthermore the intention is to present basal facts and considerations for choosing a suitable assay for different situations. 


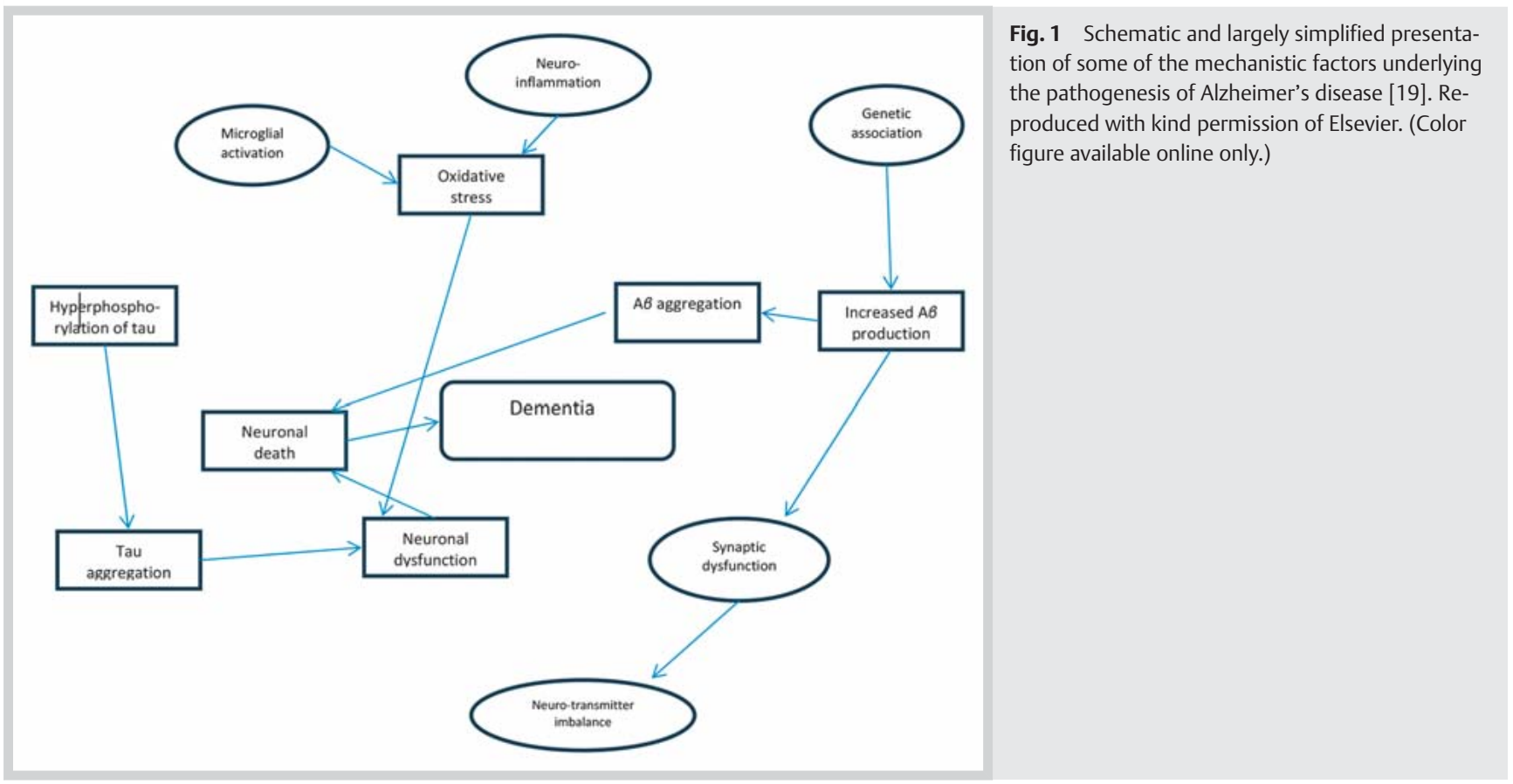

\section{Alzheimer's Disease and Screening Assays \\ $\nabla$}

Alzheimer's disease is the most common dementia in the world with estimated more than 20 million people every year developing the disease. Acknowledging the future increase in life expectancy in most countries, the number of affected people is likely to be growing rapidly [10]. Clinical manifestations of the disease are believed to be the result of pathological processes that may have been in progress for decades, and no clear causes or prognostic factors have been identified until now [11]. The neuropathological hallmarks of $\mathrm{AD}$, amyloid aggregates containing the pathological $\mathrm{A} \beta$ protein and hyperphosphorylated tau have been known and extensively studied for many years. The causality of these proteins to the pathology of the disease is, however, still not fully elucidated and in considerable part based on findings related to the rare familial forms of the disease [12].

For the last few decades, there have been immense pre-clinical and clinical efforts by the drug industry and academia to find new agents for both symptomatic and disease-modifying treatment of AD. Even though new pieces of knowledge on the disease puzzle have been identified, the outcome of drug discovery projects has so far been mostly disappointing. One of the challenges is the need of large and costly clinical trials, which has led to intense search for suitable biomarkers for disease progress. The opinion that a single cure, or single target, for Alzheimer will not likely be found is becoming more and more common $[13,14]$.

Drug discovery within the AD field has for the last 20 years been rather amyloidcentric [15]. Thus a large part of the screening efforts within this field have focused on the molecular mechanisms and proteins that are involved in the formation of $A \beta$ from its precursor APP $[16,17]$. These amyloidcentric approaches have in big part been based on the pathological mechanisms elucidated from the familial form of AD. However, the late-onset Alzheimer's disease that accounts for over $95 \%$ of all cases, and usually manifests itself after the sixth decade, has a more complex etiology and is commonly recognized as a truly multifactorial disease ( $\mathbf{O}$ Fig. $\mathbf{1}$ ). Therefore the focus on amyloid pathways has increasingly shifted to include also other mechanisms and targets for screening, including ones connected to inflammation and oxidative stress [18]. Another important mechanistic intervention approach is targeting neurotransmitter dysfunction, with cholinesterase inhibitors as the main class of compounds [19].

\section{Neurotransmittor Dysfunction: Acetylcholinesterase and Butylcholinesterase Inhibition \\ $\nabla$}

A decline in cholinergic activity in brains of Alzheimer patients and associated cognitive decline has been shown by numerous studies (e.g., [20,21]), and several of the AD drugs on the market are targeting this dysfunction. There have been some studies indicating that AchE might have a more causative role in the disease [22], but the most common view is that inhibitors of this enzyme instead offer a modest symptomatic treatment effect. In addition, the therapeutic effect is usually restricted to mild and early stages of the disease [23]. Interestingly, several of the inhibitors that are in clinical use today have natural origin (e.g., galantamine, rivastigmine, and huperzine A) [24].

As changes in both enzymatic activity and expression levels of the enzyme BChE have been reported, its involvement in AD pathology has also been proposed. In a recent review [25], Nordberg et al. conclude that different profiles in inhibiting the two esterases (AChE and BChE) are demonstrated by the presently prescribed drugs. Furthermore, it is proposed that the role of $\mathrm{BChE}$ in cholinergic dysfunction may become more pronounced as the disease progresses and that more insight into this area will be needed for elucidation of the role of dual inhibitors.

\section{Target-based assays: acetylcholinesterase and butyrylcholinesterase inhibition}

The most common assay set-ups for screening and ranking NP AchE inhibitors are based on the method by Ellman et al. [26]. This biochemical assay is built on the conversion of the substrate for AchE, acetylthiocholine iodine, followed by the reaction of its 
Table 1 Screening for acetylcholinesterase inhibitors, a few recent examples.

\begin{tabular}{|c|c|c|c|}
\hline Author, reference & Method & Special feature & Screened material \\
\hline Orhan et al. [33] & Modified Ellman, plate format & Both AchE and BChE & $\mathrm{MeOH}$-Chloroform extracts \\
\hline Andersen et al. [34] & $\begin{array}{l}\text { Modified Ellman, reaction velocity anal- } \\
\text { ysis, plate format }\end{array}$ & TLC bioautographic assay & Water and methanol plant extracts \\
\hline Ferreira et al. [35] & $\begin{array}{l}\text { Modified Ellman, reaction velocity anal- } \\
\text { ysis, cuvette assay }\end{array}$ & Antioxidant activity also assessed & $\begin{array}{l}\text { Essential oils, ethanolic extracts, } \\
\text { decoctions }\end{array}$ \\
\hline Mukherjee et al. [36] & Modified Ellman, plate format & AchE from bovine erythrocytes & Extracts \\
\hline Loizzo et al. [37] & $\begin{array}{l}\text { Modified Ellman, stop time analysis } \\
\text { ( } 20 \mathrm{~min}) \text {, plate format }\end{array}$ & Both AchE and BChE, also antioxidant activity & Extracts and fractions \\
\hline Khan et al. [38] & Modified Ellman. Column format & $\begin{array}{l}\text { Flow injection analysis (FIA) over immobilized } \\
\text { enzyme }\end{array}$ & Extracts \\
\hline Cespedes et al. [39] & Modified Ellman & $\begin{array}{l}\text { Both AchE and BChE, also AChE isolated from } \\
\text { S. frugiperda }\end{array}$ & Extracts, pure compounds \\
\hline Lai (2013) [40] & Modified Ellman, plate format & $\begin{array}{l}\text { Kinetic analysis and molecular modeling of } \\
\text { isolated compound }\end{array}$ & Isolated alkaloids \\
\hline
\end{tabular}

thiocholine product with DTNB (Ellman's reagent), to form a colored anion (5-thio-2-nitro-benzoic acid). The exact format of the assay varies, and the influences of the set-up on the results obtained are thoroughly discussed in a recent article by Järvinen et al. [27].

Another not as widely used method is the TLC bioautographic method described by Marston et al. [28]. It is based on the conversion of naphthyl acetate into naphthol and the formation of the corresponding purple-coloured diazonium dye with Fast Blue B salt. A comparison of the two colorimetric methods (Ellman and Fast Blue) is presented in the article by Di Giovanni et al. [29]. The assays for $\mathrm{BChE}$ inhibition are commonly based on the same principles as for AchE [30].

There have been several efforts for further development of the Ellman method, for example the one described by Ingkaninan et al. [31]. This study describes the development of a continuous flow-based system that allows for rapid separation, identification, and activity measurement of constituents in plant extracts. The method comprises the use of a HPLC system with on-line coupled UV, mass spectrometric and biochemical detection, continuous mixing of the reagents, and absorbance measurement at $405 \mathrm{~nm}$. If an inhibitor for AchE passes the column, less of the detected product will be formed, and this will result in a negative peak in the chromatogram.

A survey of the plants screened for their AchE inhibitory activity and the assays that were used until 2007 is presented by Mukherjee et al. [32]. O Table 1 presents a few additional examples of the methods and their developments in more recent years.

The pros of these methods are their robustness and relatively simple set-up requirements. There are plenty of reference data and results available which makes validation and comparison of the assay a straight forward process. Being a biochemical assay with stable components and a relatively slow velocity of the enzymatic reaction, it is also suitable for miniaturization and the use of automation, making it a good choice if large collections of compounds or extracts are to be assessed. However, several of these advantages inherently lead to assay limitations. For example, as the assay is almost totally 'artificial' since the enzyme is not human and the substrate and assay environment are nonphysiological, subsequent characterization of the active compounds becomes even more important than usual. Naturally, this only holds true if the aim is to find starting points for identification of compounds active in humans. Nonetheless, if the intention is to discover future drug candidates, the design of the funnel for subsequent characterization of active compounds is critical for success.

Structures of the human recombinant and eel enzymes are very similar [41]. Still, due to for example post-translational processing [42] and molecular variants of human AchE, and the lack of cellular context of the assay systems, they cannot be considered as identical, nor will inhibitors as a rule give identical results [43]. Both false positive and false negative results could be the consequence and thus seriously challenge the further drug development process.

Methodologically speaking, the limitations of using a colorimetric read out and extrinsic indication and indirect quantification of enzymatic activity with DTNB have recently been addressed. To measure color formation is always potentially a challenge, especially with natural products which frequently are strongly colored. As for the use of DTNB, it can be non-optimal if assay conditions are outside of its specific $\mathrm{pH}$ range ( $\mathrm{pH}$ 6.5-8.5), or if for example other free thiol-containing agents or reducing groups (such as oximes) are present $[44,45]$.

To address and overcome these limitations, an assay using electrochemical measurements obtained by differential pulse voltammetry was evaluated [46]. A portable potentiostat system for detection of the enzymatic product thiocholine, formed from the substrate acetylthiocholine iodide, was used. The enzyme source for AchE was human erythrocytes. The authors conclude that they have developed a label-free electrochemical detection platform which gives comparative results to the Ellman's method, and it can be further developed into a multichannel potensiostat system with high-throughput compatibility.

Yet another development of the assay is described by Min et al. [47]. They use a capillary electrophoresis method with an on-line acetylcholinesterase microreactor. In this method, immobilized AChE microreactor based on an ionic binding and film overlay is prepared followed by the substrate acetylthiocholine (either mixed with inhibitor or with no inhibitor) that is then injected into the capillary to contact the immobilized enzyme. After the enzymatic reaction, its product and unreacted substrate are detected after separation in the rest of the capillary by applying an electric potential. Through comparison with the colorimetric method and testing of both pure compounds and extracts, the method is claimed to be simple, fast, low cost, and has the advantage of allowing the re-use of the enzyme.

In an effort to reduce the cost of the enzyme in the existing TLC bioautographic method, several new substrates for AchE were 
tested and evaluated. The main finding was that the substrate 4methoxyphenyl acetate and a mixed solution of potassium ferricyanide and iron chloride hexahydrate as chromogenic agent, although being of much cheaper cost, compared well with the previous detection methods. The risk of some compounds interfering with the detection resulting in false negative data was also pointed out [48].

\section{Amyloid-Based Approaches \\ $\nabla$}

The amyloidcentric [15] approach for identifying disease-modifying compounds for treatment of $\mathrm{AD}$ is in great part based on mutation studies in genes that relate to the relatively rare but severe early onset of the disease. The central player in this approach is $A \beta$, its formation, fibrillization, aggregation and forming of the senile plaques. The factors controlling and contributing to these processes are complex, which makes identification of the disease a central cure challenging [49]. As a positive consequence, however, it gives rise to a multitude of potential opportunities for pharmacological intervention. For example, inhibition of one or several of the secretases, the enzymes involved in formation of the pathological $A \beta 42$ fragment, is frequently targeted. Also, compounds that influence trafficking of the APP and its metabolites or those that influence $A \beta$ degradation or are involved in regulation of these processes are also likely to have an effect on $\mathrm{A} \beta$ accumulation.

An important finding in our understanding of the pathological processes in the amyloid pathways was the identification and subsequent structure elucidation [50] of the aspartic proteinase BACE1 that is one of the two central enzymes in processing of the APP. Several of the products of these enzyme cleavages are considered to be important characteristics of Alzheimer's disease, making the inhibition of their formation tempting targets for drug discovery projects. $\gamma$-secretase is the other protease that in the subsequent step from BACE1 further converts its cleavage product to $A \beta$ which is the major component of the AD senile plaques [51]. Due to inherent mechanism-based toxicity (effect on Notch signaling), $\gamma$-secretase inhibition is today not considered as likely to be a viable chronic treatment strategy for AD [52].

\section{Target-based assays: $\beta$-secretase 1 inhibition}

The most common approach to assess inhibition of the BACE1 enzyme is the use of FRET technology, recombinant human enzyme and an artificial substrate with two fluorophores. These fluorophores are separated from each other, and the signal is quenched through resonance energy transfer. When cleavage of the substrate occurs, however, the quenching is terminated, and a fluorescent signal can be quantified. The increase in fluorescence is linearly related to the rate of proteolysis. There are easy-to-use kits available for this assay (for example, Pan Vera or Invitrogen) that have been used for natural product testing [e.g., $[53,54]$ ). There are also other commercially available substrates [55-57]. The assay is homogenous and as such readily suitable for both 96 and 384-well formats in automated settings. It is easy to use, robust and in addition, it easily allows for analysis and determination of enzyme kinetic parameters that are of importance for compound characterization. The FRET substrate used is a peptide fragment from the site naturally cleaved by the BACE1 enzyme. Once again the drawbacks are associated with the simplicity and artificial nature of the method. The method uses a 'man-made' substrate, and the relevance of inhibiting its cleavage by BACE1 is naturally not easy to translate to a clinical or even in vivo situation. In addition, it is known today that also BACE1 is dependent on its surroundings and behaves in a different way in different environments; for example, its efficiency to cleave APP is affected by its intracellular localization [58]. In reality, $A \beta$ is naturally not produced in cell-free biochemical environment, and the context in which the assay components (system components) exist is fundamentally important. For example, it has been known for quite some time that both APP and the secretases are all integral transmembrane proteins [59].

\section{Phenotypic assays: amyloid precursor protein processing}

Transfected cell lines are frequently used when screening for cellular and/or mechanistic activity involved in the amyloidogenic process. The genes introduced to the cell lines commonly code for one or more of the identified mutations in early onset AD. These mutations can for example occur in APP gene, and lead to elevated $\mathrm{A} \beta$ production. People carrying these mutations tend to develop the disease at relatively young ages [60]. These assays allow for assessing if and how compounds (or extracts) influence the total $A \beta$ that is released, as well as a variety of intermediates, fragments and products that originate during the amyloid-forming process. Naturally they also make it possible to study the enzymatic activities and inhibition patterns in a cellular environment.

For example, Zhu et al. [61] used a HEK293 cell line stably expressing the APP Swedish mutation [60] giving rise to elevated $A \beta$ production and release. After incubation with the inhibitor berberine - and lysis of the cells, the lysate was then analyzed for $A \beta$ and its fragments and, in this case, for BACE1 expression levels. Also the mechanism of the effect on BACE1 expression was elucidated. The detection methods were ELISA or Western blot-based. The same cell line and detection method was used by Kang et al. [62] but in addition, they also studied the effect of an Ecklonia cava extract on $\mathrm{A} \beta$ 1-42 fibril formation. These fibrils/oligomers are considered to be important in mediating amyloid neurotoxicity [63]. Other cells that have been used are the neuroblastoma cell line SH-SY5Y transfected with the gene for APP751 mutation [64] and CHO APP695 mutation [65] as well as the non-transfected human rhabdomyosarcoma A-204 and rat pheochromocytoma P-12 cells [66]. An additional elegant example of the use of a CHO cell system and ELISA-based analysis of $\mathrm{A} \beta$ 42 and 40 in a bio-activity guided fractionation process of a plant extract of Actaea racemosa is described by Findeis et al. [67]. They isolated nine active compounds and used the assay to characterize them as $\gamma$-secretase modulators. Modulators of this enzyme are considered to be potentially of value in clinical situations since modulation as contrast to inhibition affects Notch signaling to a smaller degree [68].

The advantages of these assay systems are illustrated by Liu et al. [69] who performed a screening campaign for APP modulatory activity with fifteen plant extracts used in ayurvedic and traditional Chinese medicine. Their assay was built up with the mouse neuroblastoma cell line (N2a-SwedAP) and six-well format plates, and the levels of secreted $A \beta 40$ and $A \beta 42$ were quantified by ELISA-based methods. In addition, Western blot analysis of the supernatants and cell lysis products were performed in order to analyze more in detail the mechanism of the extracts on $A \beta$ production. This is of great importance and value since $A \beta 42$ is more prone than $A \beta 40$ to form fibrils, and therefore to be more toxic 
and there are several other fragments of APP (e.g., sAPP and SAPP $\beta$ ) to consider for the pathology [70]. The quantifications of these fragments are generally made with antibody-based methods and several of them are today commercially available in ELISA formats (e.g., MyBioSource, Enzo LifeScience). This makes them relatively easy to handle and even suitable for plate analysis.

These examples are illustrative of the benefits of these phenotypic screening assays: their use allows for more detailed and uniquely designed set-ups that can give answers to mechanistically more relevant questions. These questions can also be individually phrased by the scientists in charge of the assay, leaving room for hypothesis testing and analysis. The assays have also been broadly used for screening of synthetic compound libraries. A variety of cell lines and assay formats have been evaluated for use in screening [71], a few of them being of neuronal human origin (SK-N-SH and SK-N-AST, human neuroblastoma lines and H4 neuroglioma cell line). This is obviously a further development of the assays towards an increasingly informative phenotypic setting with higher information content and better predictive value. The ideal would be to use appropriate primary human cells, but since human neuronal cells are next to impossible to get hold of, a further development of the assay is to use primary cell cultures from animals. For example, rat primary cortical neurons that release $A \beta$ for ELISA quantification can be prepared. Also effect on BACE1 enzyme activity in these cells can be measured [72].

In recent years the trend has been for APP processing screening assays to become more robust, easy to handle, and more suitable for microtiter plates. In many cases, this has led to rather expensive reagents and the need of purchasing specific ready-made kits. As the methods move from simpler overexpressing cell systems towards primary cells, they also become even more difficult to perform in bigger automated formats. An additional price to pay is the loss in robustness: the less uniform the cells used, the bigger the variation in results both within and outside the research team. The big benefit is naturally the quality and amount of data that can be obtained from the assay.

\section{Oxidative Stress}

$\nabla$

As the amyloid cascade hypothesis as the sole central cause of the sporadic form AD has growingly become questioned, an increasing awareness of other potential deficiencies and malfunctions underlying the pathology has emerged [73]. An additional and alternative theory that has been proposed is that molecular mechanisms mediating the genetically determined form of the disease differ from the late-onset $\mathrm{AD}$ and that chronic inflammation and cellular stress to neurons owing to infection, disease, or age-dependent changes are its driving force. Furthermore meta-analysis of epidemiological studies has indicated that the use of NSAIDs might lower the risk of developing AD [18]. Inflammation can be one of the mechanisms by which a redox imbalance and increase in free oxygen radicals (ROS) is created in the CNS [74]. Consequently, an alternative free radical hypothesis proposes that oxidative stress might precede the events leading to $A \beta$ oligomerization [75].

\section{Target-based assays: radical scavenging and antioxidant activity}

There is a recent review from 2012 by López-Alarcón and Denicola [76] on chemical and cell-based methods for assessing the antioxidant capacity of natural products. A number of chemical as- says are available and commonly used, for example DPPH (stable, free oxygen radical) and ORAC (measuring the fluorescent loss of a probe) methods. They are all relatively easy to set up, robust to use and low in cost. However, their use is largely limited by their inability to capture other than small fractions of the complex in vivo situation of oxidative damage. Awareness of the limitations is therefore essential. Translation of the measured activity in these assays to an effect in vivo is difficult if at all possible, and although they give information about the radical scavenging activity of compounds and extracts, they are not suitable for assessing antioxidant capacity [77]. A recommendation made by Niki [78] is to assess the capacity of antioxidant compounds and their mixtures for their effect on the levels of plasma lipid peroxidation in vitro and biomarkers of oxidative stress in vivo.

Still, instead of totally avoiding the chemical assays, they can be deployed as complements or whenever there is a need for a rapid and easy assessment of extracts and compounds. Alternatively, several of them can be used in combination, or as a "battery" of assays measuring different aspects of antioxidation thus creating more informative antioxidant profiles of the compounds and extracts. In this line, Kamdem et al. [79] have recently published their study of Melissa officinalis and its antioxidant properties based on several chemical assays. Also Venkatachalam et al. [80] have studied antioxidant properties of plant material, in their case Psidium guajava (guava), using a variety of chemical methods, such as DPPH, NO, and SO radical scavenging assays. As pointed out by the authors, to confirm the relevance of the present findings, both in vitro and in vivo studies are subsequently needed. Another approach is to combine one or several of these chemical methods with other assays built around other mechanisms of the disease. Arruda et al. [81] worked with essential oil fractions from Hedychium gardnerianum and studied, besides antioxidant properties using the DPPH method, also AchE inhibitory activity. Even more comprehensive assay set-ups have been used, including, in a study of leaf and fruit extracts of $J u$ glans regia $\mathrm{L}$. (walnut), DPPH and DMPD assays, antioxidant activity testing against $\mathrm{SO}$, NO, and $\mathrm{H}_{2} \mathrm{O}_{2}$ radicals, as well as ferric ionchelating capacity, and ferric- and phosphomolybdenum-reducing antioxidant power. Furthermore BChE and $\mathrm{AChE}$ inhibitory activities were measured [82].

\section{Phenotypic assays: cellular antioxidation}

One of the benefits of measuring cellular antioxidant activity is that the assay can be built on different types of cells in culture and that the type of cells can be chosen for their relevance as a phenoytypic set-up for the disease. Different stressors are then used, and their choice also reflects which pathway is in the focus of current interest of the investigator. In general, the inhibitor is added simultaneously or prior to the stressor, and the measured phenomena include suppression of ROS formation, oxidation of lipids, proteins, and DNA, and cell death. For example, a common method is to use human hepatocarcinoma HepG2 cells that are loaded with the redox sensor dihydrodichlorofluorescein oxidized to fluorescent dichlorofluorescein by free oxygen radicals [76]. The cell assays are naturally more informative as they also take into account factors like cell permeability and uptake which may considerably affect the assay read-out [78].

Cells systems can also successfully be used with extracts and bioactivity-guided fractionation studies. For example, an assay comprising the neuroblastoma $x$ glioma hybrid cell line NG108-15 (from rat and mouse origin), after a $\mathrm{H}_{2} \mathrm{O}_{2}$ insult, has recently been described. Neuroprotective activity was quantified with assess- 
ment of cell viability using the MTT method. Furthermore, the fluorescent probe DCFH-DA was used for labeling the ROS formed, and a flow cytometric analysis was conducted thereafter [83]. In another study, Zhao et al. [84] used rat PC12 cells and tBTH as insult and measured cell viability with the MTT method. Another example is the detailed study of the semisynthetic compound ipriflavone. The cells used in this study were SH-SY5Y cells, a subclone from a human neuroblastoma cell line, and $\mathrm{H}_{2} \mathrm{O}_{2}$ was used as oxidative insult. The SH-SY5Y cells have the advantage of being both human and of neuronal origin, besides being relatively easily cultivated. Cell death was measured by the MTT method and ROS quantified by FACScan [85]. Also Custódi et al. [86] used SH-SY5Y cells, $\mathrm{H}_{2} \mathrm{O}_{2}$ as insult, and MTT for cell viability determination. They investigated extracts from Quercus sp. and, besides assessing antioxidation, they also measured the effect of the extract on AchE and BchE inhibition.

An assay system with a phenotypic set-up that builds on the use of an even more physiologically relevant cell type has been described by Ha et al. [87]. In an extensive study of 6-shogaol, a constituent of ginger, microglia were the choice of cells for the assays. Microglia are generally considered to be the "brain-resident macrophages' and due to their involvement in immunological and inflammatory responses they can be regarded as a highly relevant cell type for the investigated mechanisms. They respond readily to changes in their microenvironment, and are for example sensitive to stimulation with LPS whereby ROS (among other factors) is released [88]. Ha et al. [87] used the mouse microglia cell line BV-2 and rat primary microglia cultures stimulated with LPS and measured a number of products including NO and iNOS activity. Their set-up allowed for determination of several additional products thus enabling a thorough investigation of the mechanisms. A limitation is obviously the complexity of assay systems including the maintenance of cell cultures. On the positive side are the relevant products measured and the use of cell lines of appropriate origin (even if from the 'wrong species').

As can be seen from previous examples, cell assays for identification of antioxidative compounds differ in how well they reflect and resemble the physiological and pathophysiological situation. In general, the greater the relevance, the more demanding will the assay performance and maintenance become. For an optimal phenotypic assay, the cell line used should naturally be of human origin and of an appropriate kind, which in the case of AD would be microglia. As primary human (and also from other species) microglia are difficult to access, and since there is no immortalized cell line readily available today, the most common approach is to use one of the rodent cell lines (e.g., BV-2, HAPI, HMO6) [88].

\section{Discussion}

$\nabla$

Still today, AD remains a huge challenge for the scientific community. After identification of the sticky $A \beta$ protein as the main component of the AD plaques in the 1980s [89], with the subsequently identified mutations in the gene coding for its precursor APP, (e.g., [90]) there was an era of cautious optimism among scientists concerning the availability of efficient treatments in a reachable future. Over the years, this amyloidcentric theory has become increasingly questioned partly because the compounds tested with these mechanisms have not shown encouraging clinical effectiveness [49]. Thus a theory of the common familial form of the disease having a deviating mechanism (or mechanisms) is becoming more and more accepted. An illustrative fact is that even though big numbers of epidemiologic and risk analyses have been conducted [91], very few clear contributing factors have keyed out from the studies. In fact, the by far greatest risk known today is old age! Consequently, AD is characterized of both several in detail elucidated contributing mechanisms and a huge complexity of networking events. Thus screening approaches for identification of future therapeutic candidates can be proposed to benefit from both target-based and phenotypic strategies.

The answers you get arise from the questions you ask Always, when initiating the process of choosing a screening assay, the first question one should consider is the purpose of the assay, in other words, what the results will be used for. Obviously, there are numerous reasons for setting up an assay: it could be to survey a collection of extracts or pure compounds or it could be to produce a publication. In many cases, it probably is to identify and characterize suitable compounds as leads. These can subsequently be optimized into potential candidate drugs or at least used for further studies on the disease mechanism of interest. How can we decide if an assay is suitable for the purpose? Logically, if the aim is to perform a rapid survey, then the assay chosen should be a fast, simple, and reproducible method of making comparisons. If, on the other hand, the aim is to find new compounds with in vivo - and potentially even clinical - efficacy in a complex disease, then the considerations in focus should be how well we understand the disease, what the important mechanisms and processes are, and what we know of the predictive value of measuring these isolated events. The bottom line is to be well aware of what the chosen assay is capable of measuring, and what it is not. In other words, a simple question will not give a complex answer and vice versa.

The streamlined process of modern drug discovery with usually high magnitude compound screening capabilities can be used for both synthetic and natural product libraries. It usually starts with an identified medical need and is connected to a hypothesis of modulating a specific target for achievement of a beneficial treatment effect. It is in many ways an attractive approach. The process is logical with a relatively linear step-by-step progress, and the complexity of methods and assays increases as the project proceeds. Different scientific disciplines co-operate with well-defined and clear responsibilities of each unit [92].

Power of phenotypic primary screening, on the other hand, might specially be underscored in such complex diseases where there still is lack of understanding and elucidation of their causative pathological mechanisms. In many cases, the assay will not be fit for extensively high throughputs, and the data obtained will need laborious processing and analysis. It seldom gives simple 'yes' or 'no' answers, and the results might even be unexpected and difficult to interpret. On the plus side, the really unique, meaningful finding might be the end result [93].

The target based reductionistic approach can in a more successful way than the phenotypic make use of structural biology and computational methods for compound optimization. A risk that on the other hand is commonly pointed out [94] is that screening for selective and specific compounds that modulate single targets leads to identification of compounds that lack end-effect on the disease. This could be caused by redundant mechanisms and pathways that will neutralize the effect on a specific target in in vivo and clinical situations. Furthermore the target-based approach is built on filtering compounds starting with less complex assays and building on more complexity later in the process. Thus if the first assay in some way is poorly chosen, by 'asking the 
wrong question', then the wrong compounds 'answers' will be picked-up thus leading inevitably to failure later on in the cascade. A careful consideration of the uniqueness of each situation and assay is therefore essential [95].

As for the phenotypic systems, the results should be more easily translatable to the disease since the measurement is done on a mechanism with several contributing pathways. On the other hand, optimization may need to be driven towards several directions and maybe results in the need of combined effect of several compounds. When elucidation of the mechanism of interaction is eventually carried out, it may turn out to be impossible to point to a single - or even to a few - well-defined pathways that could explain the observed effect [96]. Reductionism in its many forms has given us the precision in understanding target function at the molecular level, but it has also increased the risk of the researcher quantifying isolated events that lack further value [97]

Today natural products have regained their acknowledged role as source for new compound leads in screening efforts. It could be argued that due to the diversity represented by extracts and the chemical complexity of the pure natural compounds in addition to their frequently low potency interactions in biological systems, phenotypic screening methods should be the assays of choice. Nevertheless, the reductionistic approach and biochemical assays are still a useful way of natural product screening, as long as there is awareness of what they can and cannot achieve. One aspect where they have clear superiority to phenotypic assays is in the numbers of samples that they can handle. Naturally, considerations on assay design as regards to robustness and reproducibility, detection technologies, as well as miniaturization and automation should be guided by the specific need of each screening effort.

To conclude, the bottom line is to decide and carefully phrase the question that the assay can give an answer to. Obviously, if this is not properly done then the answers obtained will lack validity. This requires scoping the disease mechanisms and how each of them, including the target mechanism of the assay, contributes to the pathology. Finally knowing and in detail understanding the assay and its components will create a solid ground for interpreting the answers given by it.

\section{Conflict of Interest}

\section{$\nabla$}

The author declares no conflict of interest.

\section{References}

1 Swinney DC, Anthony J. How were new medicines discovered? Nat Rev Drug Discov 2011; 10: 507-519

2 Kell DB. Finding novel pharmaceuticals in the systems biology era using multiple effective drug targets, phenotypic screening and knowledge of transporters: where drug discovery went wrong and how to fix it. FEBS J 2013; 280: 5957-5980

3 Hughes JP, Rees S, Kalindjian SB, Philpott KL. Principles of early drug discovery. Brit J Pharmacol 2011; 162: 1239-1249

4 Cragg GM, Newman DJ. Natural products: a continuing source of novel drug leads. Biochim Biophys Acta 2013; 1830: 3670-3695

5 Mishra BB, Tiwari VK. Natural products: An evolving role in future drug discovery. Eur J Med Chem 2011; 46: 4769-4807

6 Barker A, Kettle JG, Nowak T, Pease JE. Expanding medicinal chemistry space. Drug Discov Today 2013; 18: 298-304

7 López-Vallejo F, Giulianotti MA, Houghten RA, Medina-Franco JL. Expanding the medicinally relevant chemical space with compound libraries. Drug Discov Today 2012; 17: 718-726

8 Beutler JA. Natural products as a foundation for drug discovery. Curr Protoc Pharmacol 2009; 46: 1-9
9 Schmitt EK, Moore CM, Krastel P, Petersen F. Natural products as catalysts for innovation: a pharmaceutical industry perspective. Curr Opin Chem Biol 2011; 15: 497-504

10 Ferri CP, Prince M, Brayne C, Brodaty H, Fratiglioni L, Ganguli M, Hall $K$, Hasegawa K, Hendrie H, Huang Y, Jorm A, Mathers C, Menezes PR, Rimmer E, Scazufca M. Global prevalence of dementia: a Delphi consensus study. Lancet 2005; 366: 2112-2117

11 Bendlin BB, Carlsson CM, Gleason CE, Johnson SC, Sodhi A, Gallagher CL, Puglielli L, Engelman CD, Ries ML, Xu G, Wharton W, Asthana S. Midlife predictors of Alzheimer's disease. Maturitas 2010; 65: 131-137

12 Skape SD. Alzheimer's disease and amyloid: culprit or coincidence? Int Rev Neurobiol 2012; 102: 277-316

13 Cummings JL, Banks SJ, Gary RK, Kinney JW, Lombardo JM, Ryan R, Walsh $R R$, Zhong K. Alzheimer's disease drug development: translational neuroscience strategies. CNS Spectr 2013; 18: 128-138

14 Misra S, Bikash B. Drug development status for Alzheimer's disease: present scenario. Neurol Sci 2013; 34: 831-839

15 Hardy JA, Higgins GA. Alzheimer's disease: the amyloid cascade hypothesis. Science 1992; 256: 184-185

16 De Strooper B, Vassar R, Golde T. The secretases: enzymes with therapeutic potential in Alzheimer disease. Nat Rev Neurol 2010; 6: 99-107

17 Masters CL, Selkoe DJ. Biochemistry of amyloid $\beta$-protein and amyloid deposits in Alzheimer disease. Cold Spring Harb Perspect Med 2012; 2: $1-24$

18 Krstic D, Knuesel I. Deciphering the mechanism underlying late-onset Alzheimer disease. Nat Rev Neurol 2013; 9: 25-34

19 Anand R, Gill KD, Mahdi AA. Therapeutics of Alzheimer's disease: past, present and future. Neuropharmacol 2014; 76: 27-50

20 Davies P, Maloney AJ. Selective loss of central cholinergic neurons in Alzheimer's disease. Lancet 1976; 8000: 1403

21 Mufson EJ, Counts SE, Perez SE, Ginsberg SD. Cholinergic system during the progressing of Alzheimer's disease: Therapeutic implications. Expert Rev Neurother 2008; 8: 1703-1718

22 Munoz-Torrero D. Acetylcholinesterase inhibitors as disease-modifying therapies for Alzheimer's disease. Curr Med Chem 2008; 15: 24332455

23 Tayeb HO, Yang HD, Price BH, Tazari FI. Pharmacotherapies for Alzheimer's disease: Beyond cholinesterase inhibitors. Pharmacol Ther 2012; 134: 8-25

24 Sun X, Jin L, Ling P. Review of drugs for Alzheimer's disease. Drug Discov Ther 2012; 6: 285-290

25 Nordberg A, Ballard C, Bullock R, Darreh-Shori T, Somogyi M. A review of butyrylcholinesterase as a therapeutic target in the treatment of Alzheimer's disease. Prim Care Companion CNS Disord 2013; 15

26 Ellman GL, Courtney KD, Anders VJr, Feather-Stone RM. A new and rapid colorimetric determination of acetylcholinesterase activity. Biochem Pharmacol 1961; 7: 88-95

27 Järvinen P, Vuorela P, Hatakka A, Fallarero A. Potency determinations of acetylcholinesterase inhibitors using Ellman's reaction based assay in screening: Effect of assay variants. Anal Biochem 2011; 408: 166-168

28 Marston A, Kissling J, Hostettmann K. A rapid TLC bioautographic method for the detection of acetylcholinesterase and butyrylcholinesterase inhibitors in plants. Phytochem Anal 2002; 13: 51-54

29 Di Giovannia S, Borlozb A, Urbainb A, Marston A, Hostettmann K, Carrupta PA, Reista $M$. In vitro screening assays to identify natural or synthetic acetylcholinesterase inhibitors: Thin layer chromatography versus microplate methods. Eur J Pharm Sci 2008; 33: 109-119

30 Karlsson D, Fallarero A, Brunhofer G, Guzik P, Prinz M, Holzgrabe U, Erker $T$, Vuorela $P$. Identifying and characterization of diarylimidazoles as hybrid inhibitors of butyrylcholinesterase and amyloid beta fiblil formation. Eur J Pharm Sci 2012; 45: 169-183

31 Ingkaninan $K$, de Best CM, van der Heijden R, Hofte AJP, Karabatak B, Irth $H$, Tjaden UR, van der Greef J, Verpoorte R. High-performance liquid chromatography with on-line coupled UV, mass spectrometric and biochemical detection for identification of acetylcholinesterase inhibitors from natural products. J Chromatog A 2000; 872: 61-73

32 Mukherjee PK, Kumar V, Mal M, Houghton PJ. Acetylcholinesterase inhibitors from plants. Phytomedicine 2007; 14: 289-300

33 Orhan I, Sener B, Choudhary IM, Khalid A. Acetylcholinesterase and butyrylcholinesterase inhibitory activity of some Turkish medicinal plants. J Ethnopharmacol 2004; 91: 57-60

34 Andersen A, Gauguin B, Gudiksen L, Jäger AK. Screening of plants used in Danish folk medicine to treat memory dysfunction for acetylcholinesterase inhibitory activity. J Ethnopharmacol 2006; 104: 418-422 
35 Ferreira A, Proença C, Serralheiro MLM, Araujo MEM. The in vitro screening for acetylcholinesterase inhibition and antioxidant activity of medicinal plants from Portugal. J Ethnopharmacol 2006; 108: 31-37

36 Mukherjee PK, Kumar V, Houghton PJ. Screening of Indian medicinal plants for acetylcholinesterase inhibitory activity. Phytother Res 2007; 21: 1142-1145

37 Loizzo MR, Tundis R, Conforti F, Menichini F, Bonesi M, Nadjafi F, Frega NG, Menchini F. Salvia leriifolia Benth (Laminaceae) extract demonstrates antioxidant properties and cholinesterase inhibitory activity. Nutr Res 2010; 30: 823-830

38 Khan M, Elhussein SAA, Khan MM, Khan N. Anti-acetylcholinesterase activity of Piper sarmentosum by a continuous immobilized-enzyme assay. APCBEE Procedia 2012; 2: 199-204

39 Cespedes CL, Muñoz E, Salazar JR, Yamaguchi L, Werner E, Alarcon J, Kubo I. Inhibition of cholinesterase activity by extracts, fractions and compounds from Calceolaria talcana and C. integrifolia (Calceolariaceae: Scrophulariaceae). Food Chem Toxicol 2013; 62: 919-926

40 Lai DH, Yang ZD, Xue WW, Sheng J, Shi Y, Yao XJ. Isolation, characterization and acetylcholinesterase inhibitory activity of alkaloids from roots of Stemona sessilifolia. Fitoterapia 2013; 89: 257-264

41 Dvira H, Silmanb I, Harela M, Rosenberryc TL, Sussmana JL. Acetylcholinesterase: from 3D structure to function. Chem Biol Interact 2010; 187: $10-22$

42 Ryšlavá $H$, Doubnerová V, Kavan D, Vaněk O. Effect of posttranslational modifications on enzyme function and assembly. J Proteomics 2013; 92: 80-109

43 Massoulié J, Perrier N, Noureddine H, Liang D, Bon S. Old and new questions about cholinesterases. Chemical Biol Interact 2008; 75: 30-44

44 Ramachandran S, Rami BR, Udgaonkar JB. Measurements of cysteine reactivity during protein unfolding suggest the presence of competing pathways. J Mol Biol 2000; 297: 733-745

45 Sakurada K, Ikegaya H, Ohta H, Akutsu T, Takatori T. Hydrolysis of an acetylthiocholine by pralidoxime iodide (2-PAM). Toxicol Lett 2006; 166: 255-260

46 Veloso AJ, Nagy PM, Zhang B, Dhar D, Liang A, Ibrahim T, Mikhaylichenko $S$, Aubert I, Kerman K. Miniaturized electrochemical system for cholinesterase inhibitor detection. Anal Chim Acta 2013; 774: 73-78

47 Min W, Wang W, Chen J, Wang A, Hu Z. On-line immobilized acetylcholinesterase microreactor for screening of inhibitors from natural extracts by capillary electrophoresis. Anal Bioanal Chem 2012; 404: 2397-2405

48 Yang ZD, Song ZW, Ren J, Yang MJ, Li S. Improved thin-layer chromatography bioautographic assay for the detection of actylcholinesterase inhibitors in plants. Phytochem Anal 2011; 22: 509-515

49 Mullane $K$, Williams M. Alzheimer's therapeutics: Continued clinical failures question the validity of the amyloid hypothesis - but what lies beyond? Biochem Pharmacol 2013; 85: 289-305

50 Hong L, Koelsch G, Lin X, Wu S, Terzyan S, Ghosh AK, Zhang XC, Tang J. Structure of the protease domain of memapsin 2 ( $\beta$-secretase) complexed with inhibitor. Science 2000; 290: 150-153

51 Wang $H$, Li R, Shen Y. $\beta$-Secretase: its biology as a therapeutic target in diseases. TIPS 2013; 34: 215-225

52 Golde TE, Koo EH, Felsenstein KM, Osborne BA, Miele L. $\gamma$-Secretase inhibitors and modulators. Biochim Biophys Acta 2013; 1828: 28982907

53 Jeon SY, Kwon SH, Seong YH, Bae K, Hur JM, Lee YY, Suh DY, Song KS. $\beta$ secretase (BACE1)-inhibiting stilbenoids from Smilax Rhizoma. Phytomedicine 2007; 14: 403-408

54 Sasaki H, Miki K, Kinoshita K, Koyama K, Juliawaty LD, Achmad SA, Hakim EH, Kaneda M, Takahashi K. $\beta$-secretase (BACE-1) inhibitory effect of bioflavonoids. Bioorg Med Chem Lett 2010; 20: 4558-4560

55 Zhu Z, Li C, Wang X, Yang Z, Chen J, Hu L, Jiang H, Shen X. 2,2',4'-trihydroxychalcone from Glycyrrhiza glabra as a new specific BACE1 inhibitor efficiently ameliorates memory impairment in mice. J Neurochem 2010; 114: 374-385

56 Tao J, Zhao J, Zhao Y, Cui Y, Fang W. BACE inhibitory flavanones from Balanophora involucrata Hook. f. Fitoterapia 2012; 83: 1386-1390

57 Hwang EM, Ryu YB, Kim HY, Kim DG, Hong SG, Lee JH, Curtis-Long MJ, Jeong SH, Park JY. BACE1 inhibitory effects of lavandulyl flavanones from Sophora flavescens. Bioorg Med Chem 2008; 16: 6669-6674

58 Vassar R, Kovacs DM, Yan R, Wong PC. The $\beta$-Secretase enzyme BACE in health and Alzheimer's disease: regulation, cell biology, function, and therapeutic potential. J Neurosci 2009; 29: 12787-12794

59 Small SA, Gandy S. Sorting through the cell biology of Alzheimer's disease: intracellular pathways to pathogenesis. Neuron 2006; 52: 15-31
60 Axelman K, Basun H, Winblad B, Lannfelt L. A large Swedish family with Alzheimer's disease with a codon 670/671 amyloid precursor protein mutation. A clinical and genealogical investigation. Arch Neurol 1994; 51: 1193-1197

61 Zhu F, Wu F, Ma Y, Liu G, Li Z, Sun Y, Pei Z. Decrease in the production of beta-amyloid by berberine inhibition of the expression of betasecretase in HEK293 cells. BMC Neuroscience 2011; 12

62 Kang IJ, Jeon YE, Yin XF, Nam JS, You SG, Hong MS, Jang BG, Kim MJ. Butanol extract of Ecklonia cava prevents production and aggregation of beta-amyloid, and reduces beta-amyloid mediated neuronal death. Food Chem Toxicol 2011; 49: 2252-2259

63 Cecchi $C$, Stefani $M$. The amyloid-cell membrane system. The interplay between the biophysical features of oligomers/fibrils and cell membrane defines amyloid toxicity. Biophys Chem 2013; 182: 30-43

64 Vepsäläinen S, Koivisto H, Pekkarinen E, Mäkinen P, Dobson G, McDougall GJ, Stewart D, Haapasalo A, Karjalainen RO, Tanila H, Hiltunen M. Anthocyanin-enriched bilberry and blackcurrant extracts modulate amyloid precursor protein processing and alleviate behavioral abnormalities in the APP/PS1 mouse model of Alzheimer's disease. J Nutr Biochem 2013; 24: 360-370

65 Hage S, Kleinlen-Campard P, Octave JN, Quetin-Leclerq J. In vitro screening on $\beta$-amyloid peptide production of plants used in traditional medicine for cognitive disorders. J Ethnopharmacol 2010; 131: 585-591

66 Lee TH, Part YI, Han YH. Effect of mycelial extract of Clavicorona pyxidata on the production of amyloid $\beta$-peptide and the inhibition of endogenous $\beta$-secretase activity. J Microbiol 2006; 44: 665-670

67 Findeis MA, Schroeder F, McKee TD, Yager D, Fraering PC, Creaser SP, Aus tin WF, Clardy J, Wang R, Selkoe D, Eckman CB. Discovery of a novel pharmacological and structural class of gamma secretase modulators derived from the extract of Actaea racemosa. ACS Chem Neurosci 2012; 21: 941-951

68 Hall A, Patel TR. $\gamma$-Secretase modulators: current status and future directions. Prog Med Chem 2014; 53: 101-145

69 Liu LF, Durairajan SSK, Lu JH, Koo I, Li M. In vitro screening on amyloid precursor protein modulation of plants used in ayurvedic and traditional Chinese medicine for memory improvement. J Ethnopharmacol 2012: 141: 754-760

70 Bignante EA, Heredia F, Morfini G, Lorenzo A. Amyloid $\beta$ precursor protein as a molecular target for amyloid $\beta$-induced neuronal degeneration in Alzheimer's disease. Neurobiol Aging 2013; 34: 2525-2537

71 Haugabook SJ, Yager DM, Eckman EA, Golde TE, Younkin SG, Eckman CB. High throughput screens for the identification of compounds that alter the accumulation of the Alzheimer's amyloid peptide $(A \beta)$. J Neurosci Meth 2001; 108: 171-179

72 Shimmyo Y, Kihara T, Akaike A, Niidome T, Sugimoto $H$. Flavonols and flavones as BACE-1 inhibitors: Structure-activity relationship in cellfree, cell-based and in silico studies reveal novel pharmacophore features. Biochim Biophys Acta 2008; 1780: 819-825

73 Mangialasche F, Solomon A, Winblad B, Mecocci P, Kivipelto M. Alzheimer's disease: clinical trials and drug development. Lancet Neurol 2010; 9: 702-716

74 Dumont M, Flint Beal M. Neuroprotective strategies involving ROS in Alzheimer disease. Free Radical Biology Medicine 2011; 51: 10141026

75 Sutherland GT, Chami B, Youssef P, Witting PK. Oxidative stress in Alzheimers disease: Primary villain or physiological by-product? Redox Report 2013; 18: 134-141

76 López-Alarcón C, Denicola A. Evaluating the antioxidant capacity of natural products: A review on chemical and cellular based assays. Anal Chim Acta 2013; 763: 1-10

77 Magalhães LM, Segundo MA, Reis S, Lima JLFC. Methodological aspects about in vitro evaluation of antioxidant properties. Anal Chim Acta 2008; 613: 1-19

78 Niki E. Assessment of antioxidant capacity in vitro and in vivo. Free Radical Biol Med 2010; 49: 503-515

79 Kamdem JP, Adeniran A, Boligon AA, Klimaczewski CV, Elekofehinti OO Hassan W, Ibrahim M, Waczuk EP, Meinerz DF, Athayde ML. Antioxidant activity, genotoxicity and cytotoxicity evaluation of lemon balm ( $\mathrm{Me}$ lissa officinalis L.) ethanolic extract: Its potential role in neuroprotection. Ind Crops Prod 2013; 51: 26-34

80 Venkatachalam RN, Singh K, Marar T. Phytochemical screening and in vitro antioxidant activity of Psidium guaja. Free Rad Antiox 2012; 2: 31-36

81 Arruda M, Viana H, Rainha N, Neng NR, Rosa JS, Nogueira JMF, do Carmo Barreto $M$. Anti-acetylcholinesterase and antioxidant activity of essen- 
tial oils from Hedychium gardnerianum Sheppard ex Ker-Gawl. Molecules 2012; 17: 3082-3092

82 Orhan IE, Suntar IP, Akkol EK. In vitro neuroprotective effects of the leaf and fruit extracts of Juglans regia L. (walnut) through enzymes linked to Alzheimer's disease and antioxidant activity. Int J Food Sci Nutr 2011; 62: 781-786

83 Wong DZH, Kadir HA, Ling SK. Bio-assay guided isolation of neuroprotective compounds from Loranthus parasiticus against $\mathrm{H}_{2} \mathrm{O}_{2}$-induced oxidative damage in NG108-15 cells. J Ethnopharmacol 2012; 139: 256-264

84 Zhao Y, Dou J, Wu T, Aisa HA. Investigating the antioxidant and acetylcholinesterase inhibition activities of Gossypium herbaceam. Molecules 2013; 18: 951-962

85 Xiao Z, Huang C, Wu J, Sun L, Hao W, Leung LK, Huang J. The neuroprotective effects of ipriflavone against $\mathrm{H}_{2} \mathrm{O}_{2}$ and amyloid beta induced toxicity in human neuroblastoma SH-SY5Y cells. Eur J Pharmacol 2013; 721: 286-293

86 Custódio L, Patarra J, Alberício F, Neng NR, Nogueira JMF, Romano A. Extracts from Quercus sp. acorns exhibit in vitro neuroprotective features through inhibition of cholinesterase and protection of the human dopaminergic cell line SH-SY5Y from hydrogen peroxide-induced cytotoxicity. Ind Corps Prod 2013; 45: 114-120

87 Ha SK, Moon E, Ju MS, Kim DH, Ryu JH, Oh MS, Kim SY. 6-shogaol, a ginger product, modulates neuroinflammation: A new approach to neuroprotection. Neuropharmacol 2012; 63: 211-223
88 Figuera-Losasa M, Rojas C, Slusher BS. Inhibition of microglia activation as a phenotypic assay in early drug discovery. JBS 2014; 19: 17-31

89 Masters CL, Simms G, Weinman NA, Multhaupt G, McDonald BL, Beyreuther K. Amyloid plaque core protein in Alzheimer disease and Down syndrome. Proc Natl Acad Sci 1985; 83: 4245-4249

90 Hardy J. Framing $\beta$-amyloid. Nat Gen 1992; 1: 233-234

91 Imtiaz B, Tolppanen AM, Kivipelto M, Soininen $H$. Future directions in Alzheimer's disease from risk factors to prevention. Biochem Pharmacol 2014; 88: 661-670

92 Macarrón R, Hertzberg RP. Design and implementation of high throughput screening assays. Mol Biotechnol 2011; 47: 270-285

93 Lee JA, Uhlik MT, Moxham CM, Tomandl D, Sall DL. Modern phenotypic drug discovery is a viable, neoclassic strategy. J Med Chem 2012; 55: 4527-4538

94 Butera J. Phenotypic screening as a strategic component of drug discovery programs targeting novel antiparasitic and antimycobacterial agents. J Med Chem 2013; 56: 7715-7718

95 Swinney DC. The contribution of mechanistic understanding to phenotypic screening for first-in-class medicines. J Biomol Screen 2013; 18: $1186-1192$

96 Lee LA, Berg EL. Neoclassic drug discovery: The case for lead generation using phenotypic and functional approaches. J Biomol Screen 2013; 18: $1145-1155$

97 Winquist RJ, Mullane K, Williams $M$. The fall and rise of pharmacology (Re)defining the discipline? Biochem Pharmacol 2014; 87: 4-24 